\title{
Game over: cartas, rol y comida
}

SARA BADIA CLIMENT

Universitat de València-Máster en Estudios Hispánicos Avanzados

sabacli@alumni.uv.es

Amparo Alemany Martínez

Universitat de València-Máster en Estudios Hispánicos Avanzados

amaram5@alumni.uv.es

Resumen: El presente artículo propone tres actividades de carácter gamificado y experiencial para las clases de E/LE enfocadas a un nivel A1+: un juego de cartas basado en el Cards Against Humanity (2011), una cata de comida inspirada en Master Chef y un juego de rol mediatizado a través de la plataforma Classcraft (2016). Estas están destinadas a reforzar contenidos gramaticales y léxicos como los adjetivos y la flexión de género, los usos de datos personales o la construcción de oraciones simples. Además de ello, el carácter flexible de estas actividades permite trabajar con los componentes interculturales, socioculturales y afectivos.

Palabras clave: gamificación, aprendizaje experiencial, rol, A1+.

\section{Game over: cards, role playing games and food}

Abstract: In this paper three activities of gamification and experiential learning for level A1+ are proposed: a card game based on Cards Against Humanity, a food tasting inspired on the tv program Master Chef and a role game developed in the platform Classcraft. The aim of these activities is to improve grammatical and lexical contents like adjectives, gender flexion, use of personal data or construction of simple sentences. Additionally, the flexibility of this activities allows us to work with intercultural, sociocultural or affective components.

Key words: gamification, experiential learning, role game, A1+.

\section{Introducción}

En la didáctica aplicada a E/LE, el componente lúdico es esencial como medio para conseguir afianzar los conocimientos del estudiante mediante la inclusión de las características de los juegos (puntuaciones, objetivos, superación, etc.) en la dinámica educativa. Además de ello, esta clase de mecánicas de ludificación del aula traen consigo un clima en el que todo alumno puede participar independientemente del perfil que tenga (Sánchez Benítez 2012: 24-26), debido a que consiguen que el aprendizaje se vuelva un reto. Por este motivo, en este artículo conceptos como ludificar o gamificar $^{1}$ (Foncubierta y Rodríguez 2014; Alejaldre Biel y García Jiménez 2015) garantizan que el alumno no vea en la L2 una barrera, sino una oportunidad. Mediante esta perspectiva,

1 Se utilizarán ambos términos de manera indistinta en este trabajo, debido a que la bibliografía consultada utiliza ambos (Sánchez Benítez 2010; Mora 2013; Foncubierta y Rodríguez 2014; etc.). 
se activa el componente afectivo (Morgan 2006) para conseguir que todo aprendiente que esté dentro del universo del juego recuerde, no únicamente un contenido, sino una manera en la que está aprendiéndolo, fijándolo y, con ello, divirtiéndose. El juego es un componente intrínseco al aprendiente, nadie tiene que enseñarle a jugar, pero sí a aprender jugando: «El juego es más viejo que la cultura; pues, por mucho que estrechemos el concepto de ésta, presupone siempre una sociedad humana, y los animales no han esperado a que el hombre les enseñara a jugar» (Huizinga 2007: 7).

Por este motivo, proponemos tres actividades que gamifican contenidos tanto gramaticales como léxicos: en primer lugar, «¿A qué sabe?» (§ 4.1), en segundo lugar, aprovechando lo afianzado mediante la primera secuencia, «Cartas contra estudiantes de E/LE» (§ 4.2) y, finalmente una aventura a través de la plataforma Classcraft (§ 4.3). Estas son propuestas didácticas pensadas en un primer momento para un grupo de aprendientes (unos 8-10 alumnos) de origen chino (entre 18-20 años) que parten de un nivel A1+. No obstante, las características de la propuesta y el diseño de materiales ( $\S$ 3 ) hace que puedan adaptarse a cualquier nivel en el que el aprendizaje del alumno se encuentre y sean totalmente flexibles en cuanto a los contenidos que trabajan.

\section{Objetivos generales y específicos}

El presente artículo pretende mostrar un total de tres actividades con una serie de objetivos comunes: (1) proporcionar los medios para que los aprendientes de español de un nivel $\mathrm{A} 1+$ adquieran las herramientas lingüísticas necesarias para saber presentarse y conseguir que una serie de interlocutores puedan entenderlos, (2) para ello se profundizará en el ámbito oral (previa explicación gramatical) con el fin de que adquieran destrezas para que puedan describir cualidades físicas y psíquicas (feliz/triste, alto/bajo, simpático/antipático, etc.) tanto propias como de otras personas y así, (3) poder llegar a describir y describirse con el fin de poder comunicar lo aprendido fuera del entorno académico. En resumen, tres objetivos que les llevarán a tener un primer contacto con el idioma y el mundo hispanohablante y que a su vez se encuentran instaurados de esta manera en el MCER:

Es capaz de comprender y utilizar expresiones cotidianas de uso muy frecuente así como frases sencillas destinadas a satisfacer necesidades de tipo inmediato. Puede presentarse a sí mismo y a otros, pedir y dar información personal básica sobre su domicilio, sus pertenencias y las personas que conoce. Puede relacionarse de forma elemental siempre que su interlocutor hable despacio y con claridad y esté dispuesto a cooperar ${ }^{2}$

MCER, 2002: 26

Por este motivo, los objetivos específicos que deseamos que adquiera nuestro alumnado a partir de las tres actividades que posteriormente se propondrán serán los siguientes:

a. Saber decir y preguntar por el nombre para poder presentarse con exactitud, por ejemplo: «Me llamo Luna».

b. Saber decir y preguntar la edad, con el fin de dar a conocer a un posible interlocutor datos personales básicos, es decir, «Tengo 20 años».

${ }^{2}$ La negrita es nuestra. 
c. Saber describir cualidades propias y de otros para poder completar una panorámica personal que envuelve una breve descripción tanto física («Soy alta») como psicológica («Estoy alegre»).

d. Saber decir y preguntar la localidad de origen. Con este objetivo a su vez se pretende dar a conocer sucintamente contenidos socioculturales tanto de España como del país o países de origen de nuestro alumnado sea del país que sea: comida típica de China, música, lugares, etc.

\section{Contenidos y diseño de materiales}

Las actividades que se proponen han sido consideradas como una clase de moldes con los que poder trabajar distintos contenidos. Debido a ello, su realización se ha llevado a cabo dentro del marco de la gamificación (Báez Jaitkin 2016) como una manera lúdica en la que aula de E/LE permite adquirir ciertos conocimientos de manera lúdica como forma de evitar técnicas que se consideran menos efectivas, tales como la memorización directa de listas de verbos, frases hechas o fórmulas rutinarias. En cuanto a las tres actividades que se reseñan, una de ellas es de creación propia, la cata de comida, y las otras dos están basadas en un entorno web (el Clascraft, 2016) y un juego de mesa (Cards against humanity, 2011) que, sin embargo, sí que se han adaptado en su totalidad para esta propuesta.

En concreto, la propuesta pretende centrarse, a nivel gramatical, en el refuerzo de las oraciones interrogativas, el adjetivo calificativo y la flexión de género y número regular. En el apartado léxico, por su parte, debido a que el eje conductor de estas actividades son las descripciones y el uso de la modalidad interrogativa, se tratará de repasar y aumentar la cantidad de léxico disponible en relación con las cualidades físicas y psicológicas, los colores básicos, y el vocabulario básico de geografía y del transporte básico. Asimismo, se pretenderá que el alumnado sea capaz de utilizar imágenes u otros recursos (como señalar una parte del cuerpo) para, por una parte, promover estrategias metacognitivas y, por otra, para utilizarlo en caso de olvido o descuido de un término mientras se habla.

Además, otro de los aspectos que se trabajará será la adquisición de valores interculturales, debido a que a través de las actividades pueden surgir preguntas durante la interacción del alumnado entre sí y con los contenidos presentados. De este modo: «Educar en la habilidad de comparar bajo una visión crítica otras formas de hacer y actuar más allá de los estereotipos, interpretar sus efectos y conseguir relacionar estos con las causas intrínsecas para comprender la verdadera intención del mensaje.» (Moreno Moreno y Atienza Cerezo 2016: 9).

Es decir, se pretende que los estudiantes se interroguen sobre ciertos comportamientos de sus compañeros o de la cultura española con el fin de interpretar de la manera más adecuada el mensaje que estos tratan de transmitirles ${ }^{3}$. Del mismo modo, otro de los aspectos que se puede trabajar es el componente afectivo dentro del aula de E/LE ${ }^{4}$, mediante el cual se intentará desligar la falta de autoestima o la ansiedad que genera la

\footnotetext{
${ }^{3}$ Este aspecto se tratará de manera más profunda en la actividad 3.

${ }^{4}$ Se incluye tanto en el MCER como en el Plan Curricular del Instituto Cervantes; además de trabajarse por diversos autores como Arnold Morgan (2006).
} 
imposibilidad (en este nivel) de mantener una comunicación fluida mediante la gamificación de las tareas que se proponen.

Por tanto, se recogerán los contenidos presentados y se volcarán, tal y como se ha anunciado, en tres actividades que ayuden a su adquisición y desarrollo: las dos primeras concebidas como actividades de refuerzo y/o descanso («Cartas contra estudiantes de $\mathrm{E} / \mathrm{LE} » \mathrm{y}$ «¿A qué sabe?» $\mathrm{y}$, la última, como tarea final semidirigida (el «Nos vamos de aventura»).

\section{Tres actividades para todos los gustos}

\section{1. ¿A qué sabe?}

El aprendizaje cobra sentido cuando se relaciona directamente con nuestra experiencia y nuestra afectividad (Morgan 2006). Por este motivo, la comida puede ser un punto de anclaje de conocimientos que se puede utilizar para reforzar la adquisición de ciertos contenidos, como el vocabulario relacionado con los sabores. En este sentido las preferencias sensoriales activan la memoria a largo plazo (Núñez París 2008) mediante la asociación entre sabor y olor con el contenido lingüístico que se le vincula. Lo sensorial como componente cognitivo en el aprendizaje puede llevarse a cabo mediante la ludificación a través, por ejemplo, del trabajo intercultural en el aula, ya que se puede compartir tanto aquellos productos típicos de la cultura de la lengua meta (promovidos por el profesor) como los que pertenezcan a la de los alumnos.

En concreto, esta propuesta pretende centrarse en el uso de los distintos tipos de salsas para reforzar el uso de adjetivos como picante, dulce o salado. De esta manera se favorece la utilización de realia en el aula, es decir, objetos que se pueden utilizar en la vida cotidiana, en este caso la comida, pero aplicados al ámbito del aula de E/LE con el fin de «presentar el vocabulario ya que con ellas podemos ilustrar las palabras que queremos enseñar sin necesidad de recurrir a la lengua materna» (Álvarez Mennuto 2011: 14). Para ello, se dividirá la clase en grupos de 5 personas (puede emplearse cualquier técnica, por ejemplo, se podría organizar al alumnado repartiendo post-its de colores) y se les repartirá un juego de cartas que contengan, por un lado, el adjetivo escrito y, por otro, una imagen que ayude a identificarlo tal y como se puede observar en el ejemplo:

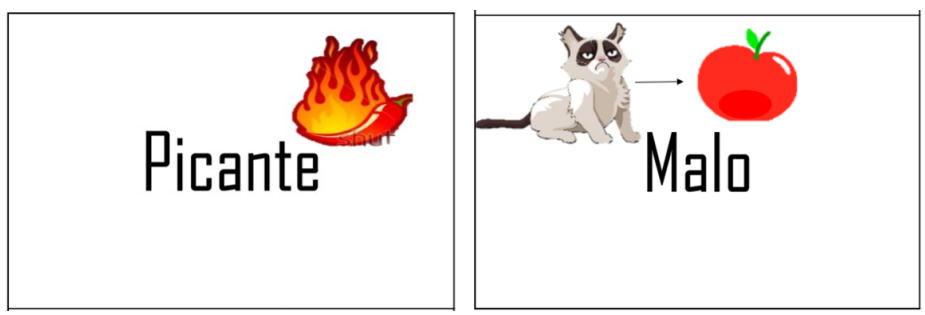

Imagen 1. Ejemplo de cartas con sabores

Por último, se repartirán distintos botes con las salsas, unos biscotes y un trozo de tela para cubrir los ojos. A continuación, se explicará el desarrollo de la actividad, que consistirá en que cada grupo escoja a un integrante por turno, que se le vendará los ojos y se le dará a probar una de las opciones. Después, el alumno tendrá que escoger una de 
las cartas que crea que identifique el sabor de la comida que ha probado para, posteriormente, descubrir cuál ha sido la elección de sus compañeros. Este proceso se puede repetir hasta que el profesor considere terminada la actividad, pero se recomienda que no excedan los 20 minutos (también depende de los tipos de comida que se haya dispuesto).

\subsection{Cartas contra estudiantes de $\mathrm{E} / \mathrm{LE}$}

La construcción de oraciones a veces ocasiona cierta dificultad para los aprendientes de español. Por este motivo, el hecho de formar frases correctas puede suponer un reto aprovechable para insertar un nuevo juego y, de este modo, volver a fomentar el ambiente lúdico en el aula. Para su realización, será necesario que los alumnos dominen la flexión simple de los sustantivos y los adjetivos, así como el uso de verbos en tiempo presente.

La propuesta aprovechará la distribución en grupos de los estudiantes para la actividad anterior. Luego, se propondrá a los alumnos un juego basado en el Cards Against Humanity (2011) que, en este caso, se ha renombrado y adaptado para la clase de E/LE. El juego consiste en completar los huecos de las frases de unas cartas negras (cartas de pregunta) mediante los adjetivos que aparecen en las cartas blancas (cartas de respuesta). Para ello, cada alumno dispondrá de 5 cartas blancas con adjetivos, menos uno de ellos, que por turno sacará una carta negra y la dejará a la vista de todos para que el resto de estudiantes la completen con la carta blanca que deseen (estas cartas se dejan bocaabajo para que el estudiante con la carta negra no pueda leerlas). Para finalizar el turno, el estudiante que ha dejado la carta de pregunta leerá en voz alta todas las respuestas dadas por sus compañeros y con ello tratará de utilizar la concordancia entre los adjetivos y el resto de palabras de la oración.

Por lo tanto, los aprendientes tienen que intentar elaborar construcciones gramaticalmente correctas con adjetivos que se relacionen con las frases que les dan las cartas de pregunta. Asimismo, si la actividad sigue el curso esperado, terminada una primera ronda, se puede pedir a los alumnos que intenten responder de forma absurda o graciosa (por ejemplo, «las montañas son altas») y que traten de dar un por qué. Con ello, los alumnos tendrán la oportunidad de trabajar la interacción oral en un ambiente más distendido.

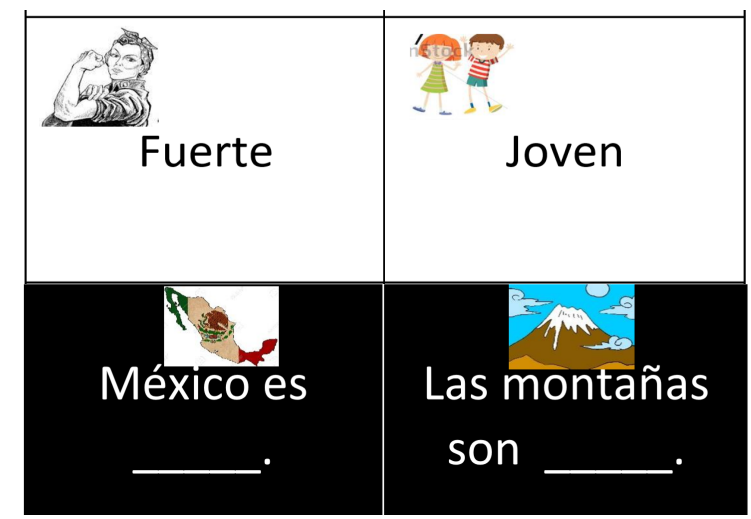

Imagen 2. Ejemplo de cartas con adjetivos y frases 


\subsection{Nos vamos de aventura}

«Hay un jefe malo que asusta al pueblo y les obliga a realizar pruebas para salir de él.»

Con esta oración se introducirá a los alumnos a esta última macroactividad: «Nos vamos de aventura con el Classcraft (2016)». Mediante esta herramienta, el profesor puede crear un mapa (imagen 3) en el que se señalan los distintos pasos que tienen que realizar los estudiantes durante toda la clase y que el profesor irá indicando. Además, se podrán crear distintos personajes (Imagen 4) que representen a los alumnos con alguna clase de «poder» que puedan utilizar en el transcurso de las actividades.

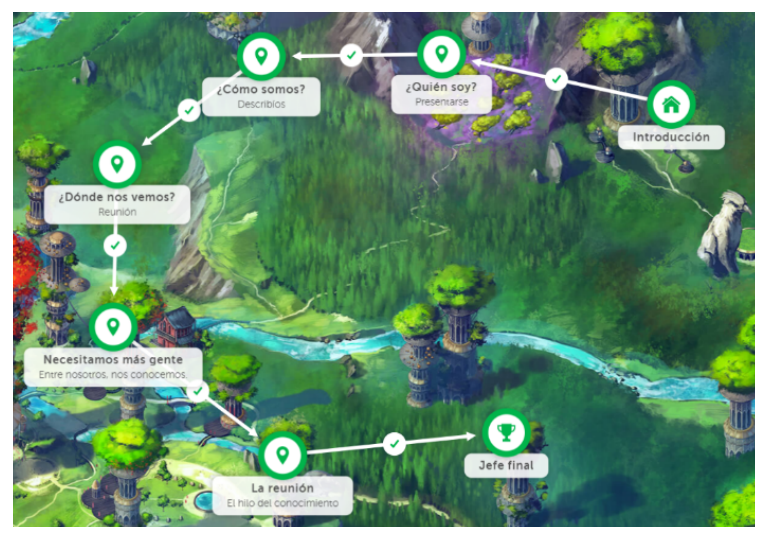

Imagen 3. Mapa de tareas del Classcraft (2016)

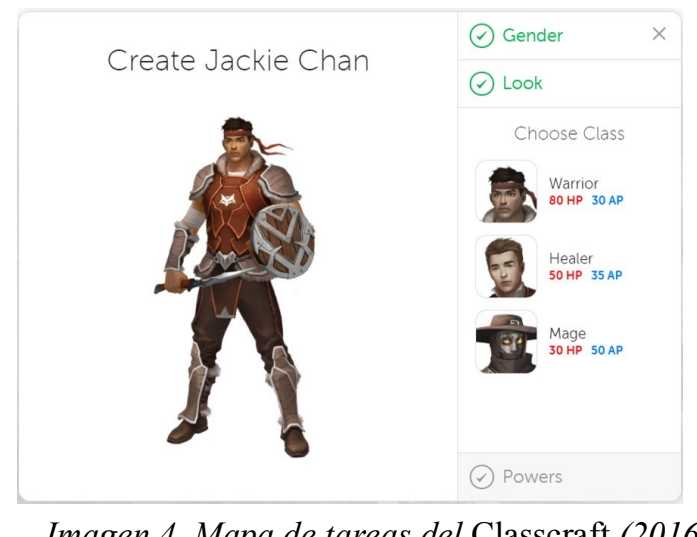

Imagen 4. Mapa de tareas del Classcraft (2016)

De este modo, tal y como señalan Quintanilla y Ferreira (2010), se contextualiza el enfoque por tareas y se adapta para un alumnado que aún pueda presentar dificultades en la comprensión de actividades más complejas. Asimismo, el hecho de utilizar la tecnología fomenta la atención del alumnado, ya que estos, especialmente los jóvenes, están permanentemente rodeados de estos aparatos con los que están muy familiarizados.

La propuesta, por tanto, se basará en una serie de microactividades preparatorias que se explicitarán a continuación a modo de ejemplo. Todas ellas, como se ha dicho, estarán dirigidas a preparar a los estudiantes para enfrentarse a una tarea final en la que diseñarán una tarjeta identificativa con los datos de los compañeros que habrán podido aprender a través de la aventura: 
¿Quién soy?

«Primero, presentarse. Para vencer necesitáis conoceros: buscamos a un compañero y preguntamos su nombre, su edad y su ciudad de origen.»

La primera actividad que se realice llevará a los estudiantes a presentarse entre ellos, ya que tienen que conocer y recordar los datos de sus compañeros. Se preguntarán por los datos personales y esperarán a las instrucciones del profesor. Con ello, repasarán el contenido de la primera sesión en el que tenían que utilizar sus datos personales en distintas tareas.

¿Cómo somos?

«Necesitáis más ayuda. Antes, nos describimos para estudiar las cualidades físicas de mi pareja. Lo escribimos en un papel para recordarlo.»

En esta ocasión, el alumnado tendrá que definir a su compañero y apuntar los rasgos físicos que más destaquen del otro junto con una característica de su personalidad muy visible (si se diera el caso) con el fin de facilitar las siguientes actividades. El profesor debe revisar la actividad y sugerir alternativas que ayuden a sus alumnos a ser corteses en sus descripciones, bien evitando ciertos adjetivos con carga negativa bien atenuando (Albelda y Barros 2013: 37-41) su aparición con el uso, por ejemplo, de un diminutivo: «eres un poco bajo».

¿Dónde nos vemos?

«Necesitáis pensar un punto de reunión. Decidimos el lugar de la clase al que ir.» (Imagen 5)

Antes de separarse de su pareja, tendrán que decidir en qué lugar volverán a verse y, por ello, se habilitarán distintos lugares del aula en los que podrán concertar una reunión, ya que la siguiente fase requiere que se separen y busquen a un nuevo compañero para ayudarles contra el "jefe" final.

Necesitamos más gente

«Necesitáis más conocimiento y juntar a más gente. Vais a buscar otro compañero, presentaos y vais a describir a vuestro anterior compañero. Luego nos reunimos todos en un punto de la clase.»

Los alumnos buscarán otro estudiante con el que compartir los datos personales y las cualidades tanto propias como de su antiguo compañero con el fin de que puedan reconocerse en el siguiente paso de la tarea. Cuando terminen, tendrán que ir reuniéndose hasta terminar toda la clase en un mismo punto.

\section{La reunión: el hilo del conocimiento}

«Antes de enfrentarse al jefe, practicáis vuestros conocimientos. Vais a decir una cualidad o dato personal y pasaos el hilo del conocimiento (ovillo). Vais a quedaros con un trozo del cordel cada vez.»

En esta actividad se pondrán en marcha los conocimientos adquiridos a través de todas las tareas anteriores. Los alumnos tendrán que dar un dato propio cada vez que el ovillo caiga en sus manos. Para ello, deben utilizar frases y estructuras que acompañen al dato como «me llamo Mey» o «soy alta». 


\section{El jefe final: el profesor}

«Ahora es el momento. El jefe final os sonríe y os dice "vais a mostrar vuestro conocimiento entre vosotros, luego me iré".»

En la tarea final los alumnos tendrán que demostrar lo que han aprendido de sus compañeros a través de las actividades anteriores y, así, poner en práctica lo aprendido en ellas. El profesor formará grupos de 5 estudiantes y les pedirá que realicen una especie de documentos de identidad con su nombre, edad, procedencia, gustos, habilidades y otros datos que hayan podido compartir con sus compañeros (Imagen 5). Una vez terminados, se juntarán todas las tarjetas en un montón y el profesor sacará una de la que leerá todos los datos apuntados menos el nombre y los apellidos. Finalmente, los alumnos tendrán que tratar de averiguar de qué compañero se trata.

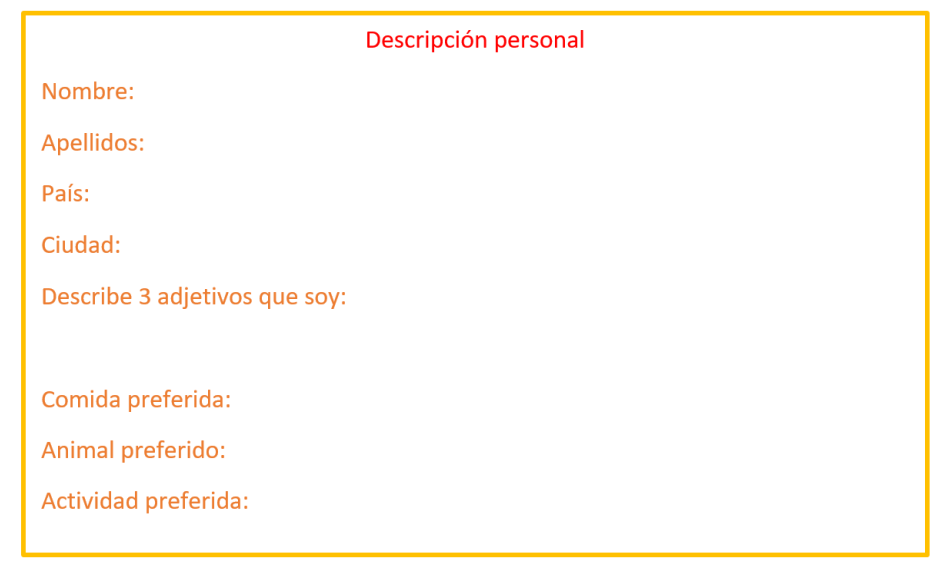

Imagen 5. Mapa de tareas del Classcraft (2016)

Finalizada la actividad, el profesor pedirá a sus alumnos que se autoevalúen con una rúbrica que se expondrá en el siguiente apartado $\mathrm{y}$, luego, se contrastará con la evaluación ofrecida por el docente. Asimismo, se expondrá a toda la clase de forma general los errores más comunes detectados en el alumnado y, también, sus fortalezas con el fin de que sean conscientes de ellos. Además, siguiendo la dinámica de rol instaurada, se pueden hacer comentarios sobre el comportamiento a nivel de personajes pertenecientes a una historia.

\section{Evaluación}

La evaluación que proponemos ${ }^{5}$ llevar a cabo sería continua, esto es, se evalúa el proceso en el aprendizaje desde la primera actividad hasta la última (la creación de una aventura en Classcraft), considerada como una macroactividad guiada por el profesor. Asimismo, también se pretende que la corrección sea integradora, es decir, se tendrán en cuenta las capacidades y no única y exclusivamente los conocimientos adquiridos. Además, se tendrá en cuenta: la comprensión de las tareas y actividades realizadas, la utilidad que para el alumnado pueden tener dichas actividades, la asimilación del

\footnotetext{
${ }^{5}$ En cualquier caso, esta propuesta es susceptible de modificaciones.
} 
contenido teórico-gramatical y la mejora de las destrezas lingüísticas. No obstante, cabe decir que:

Toda medición o valoración es una forma de evaluación, pero en un programa de lenguas se evalúan aspectos, no propiamente del dominio lingüístico, como la eficacia de métodos y materiales concretos, el tipo y la calidad del discurso producido a lo largo del programa, la satisfacción del alumno y del profesor, la eficacia de la enseñanza, etc.

MCER, 2002: 177

Partiendo de esto, se propondrá una rúbrica general ${ }^{6}$ de todos los contenidos trabajados en la asignatura y, de forma separada, en la tarea final donde se comprobará que los estudiantes han sido capaces de adquirir los conocimientos que se han pretendido reforzar durante las actividades. Esta rúbrica, además, se entregará a los alumnos para que puedan seguir su propia evolución a lo largo de las actividades y sean conscientes, principalmente, de aquello que el profesor pretende evaluar.

\begin{tabular}{|c|c|c|c|c|}
\hline Nivel oral (EIO) & Nivel escrito & Nivel auditivo & Nivel de lectura & Gramática \\
\hline $\begin{array}{l}\text { Sabe dar información } \\
\text { sobre sí mismo y } \\
\text { presentar a un } \\
\text { compañero sin } \\
\text { cometer apenas } \\
\text { vacilaciones. Conoce } \\
\text { el ambiente donde se } \\
\text { mueve. }\end{array}$ & $\begin{array}{l}\text { No comete faltas de } \\
\text { ortografía en palabras } \\
\text { que ha memorizado } \\
\text { previamente. Sabe } \\
\text { escribir su nombre, } \\
\text { edad y alguna } \\
\text { cualidad suya o de } \\
\text { sus compañeros. }\end{array}$ & $\begin{array}{l}\text { Comprende a nivel } \\
\text { semántico ciertos usos } \\
\text { de los adjetivos } \\
\text { regulares vistos en las } \\
\text { clases, sabe distinguir } \\
\text { cuando le llaman y } \\
\text { saludan. }\end{array}$ & $\begin{array}{l}\text { Comprende } \\
\text { segmentos pequeños } \\
\text { de textos donde haya } \\
\text { presentaciones. } \\
\text { Entiende los } \\
\text { enunciados de las } \\
\text { actividades de clase. }\end{array}$ & $\begin{array}{l}\text { Ha adquirido con } \\
\text { fluidez las } \\
\text { herramientas para } \\
\text { manejar los adjetivos, } \\
\text { frases simples de } \\
\text { presentación. }\end{array}$ \\
\hline $\begin{array}{l}\text { Comete vacilaciones } \\
\text { a la hora de } \\
\text { presentarse a sí mismo } \\
\text { y a los compañeros. }\end{array}$ & $\begin{array}{l}\text { Comete faltas de } \\
\text { ortografía en palabras } \\
\text { memorizadas y no } \\
\text { sabe del todo } \\
\text { desenvolverse con el } \\
\text { nivel escrito. }\end{array}$ & $\begin{array}{l}\text { Comprende a medias } \\
\text { el significado de los } \\
\text { adjetivos dados en } \\
\text { clase y duda en el } \\
\text { momento en el que lo } \\
\text { saludan hay que } \\
\text { presentarse. }\end{array}$ & $\begin{array}{l}\text { Comprende a medias } \\
\text { segmentos breves de } \\
\text { oraciones y no } \\
\text { entiende } \\
\text { completamente los } \\
\text { enunciados que se } \\
\text { han visto en clase. }\end{array}$ & $\begin{array}{l}\text { Ha entendido } \\
\text { medianamente la } \\
\text { gramática vista en } \\
\text { clase pero no se } \\
\text { desenvuelve todavía } \\
\text { con el manejo de la } \\
\text { misma. }\end{array}$ \\
\hline $\begin{array}{l}\text { Se queda en silencio } \\
\text { completamente al } \\
\text { intentar efectuar una } \\
\text { interacción y no sabe } \\
\text { responder a las } \\
\text { preguntas que se le } \\
\text { efectúan. }\end{array}$ & $\begin{array}{l}\text { No se maneja del } \\
\text { todo todavia con el } \\
\text { sistema de escritura } \\
\text { español. }\end{array}$ & $\begin{array}{l}\text { No entiende lo que se } \\
\text { dice, no existe un } \\
\text { input comprensible. }\end{array}$ & $\begin{array}{l}\text { No comprende } \\
\text { oraciones breves ni } \\
\text { entiende } \\
\text { debidamente la } \\
\text { finalidad de los } \\
\text { ejercicios que se } \\
\text { efectúan en clase. }\end{array}$ & $\begin{array}{l}\text { No comprende la } \\
\text { gramática y no se } \\
\text { desenvuelve } \\
\text { correctamente con } \\
\text { ella. }\end{array}$ \\
\hline
\end{tabular}

Tabla 1. Rúbrica de evaluación

\section{Conclusión}

El aprendizaje de una lengua lleva consigo el juego de competencias y destrezas que el propio aprendiente debe de ir adquiriendo conforme avanza en sus niveles de aprendizaje. Sin embargo, lo lúdico resulta el perfecto adhesivo emocional (Mora 2013) con el que fijar los conocimientos a largo plazo (Foncubierta y Rodríguez 2014). De este modo, las tres actividades pretenden trabajar contenidos propios de un nivel A1+ desde perspectivas relacionadas, por un lado, con la gamificación (Sánchez Benítez 2010) y, por otro, con la integración de contenidos en contextos y experiencias.

\section{Bibliografía}

Álvarez Mennuto, Alexandra (2011). «Objetos valiosos en la clase de E/LE», Centro

6 Para su realización, se ha seguido el Plan Curricular del Instituto Cervantes (2006) y las recomendaciones de Conde y Pozuelos (2010: 79) sobre la realización de «plantillas de evaluación». 
Virtual Cervantes, Actas de las IV Jornadas Didácticas del Instituto Cervantes de Manchester, 13-18. Recuperado el 09/05/18, de: https://cvc.cervantes.es/ensenanza/biblioteca_ele/publicaciones_centros/PDF/mancheste r_2011/04_alvarez.pdf

Albelda MARCO, Marta y M. ${ }^{\mathrm{a}}$ Jesús BARros GARCíA (2013). La cortesía en la comunicación. Madrid: Arco/Libros.

AlejAldRE BIEL, Leyre y Antonia GARCÍA JiMÉNEZ (2015). «Gamificar: El uso de los elementos del juego en la enseñanza de español». L Congreso: La cultura hispánica: de sus orígenes al siglo XXI, Burgos, 73-83.

ARNOLD MORGAN, Jane (2006). «Los factores afectivos en el aprendizaje del español como lengua extranjera». Études de linguistique appliquée, 144.

BÁEZ JAITKIN, Clara Elizabeth (2016). «Gamificación, ¿reto o normalidad en el proceso de enseñanza aprendizaje?». Actas del XIII Encuentro Práctico de ELE del Instituto Cervantes de Nápoles, 14-22. Recuperado el 01/05/18, de: https://cvc.cervantes.es/ensenanza/biblioteca_ele/publicaciones_centros/PDF/napoles_2 016/03_baez.pdf

CONSEJO DE EUROPA (2002). Marco común europeo de referencia para las lenguas: aprendizaje, enseñanza, evaluación. Madrid: MECD- Anaya, Instituto Cervantes.

Dillon, Josh et alii (2011). Cards Against Humanity. Recuperado el 11/04/2018, de https://cardsagainsthumanity.com/\#download

ESTAIRE, Sheila (2007). La enseñanza de lenguas mediante tareas: principios y planificación de unidades didácticas. Recuperado el 01/05/18, de: http://www.nebrija.es/espanolparainmigrantes/flash /ensenar/ PDF/articulo-tareas. pdf

FONCUBIERTA, José Manuel y Chema RodRíGUEZ (2014). «Didáctica de la gamificación en la clase de español». Recuperado el 01/05/18, de: https://www.edinumen.es/spanish_challenge/gamificacion_didactica.pdf

HuIzINGA, Johan (2007). Homo ludens. Barcelona: Editorial Alianza.

MoRA, Francisco (2013). Neuroeducación. España: Alianza-Editorial

Moreno Moreno, Rosa María y Encarna ATIEnZA Cerezo (2016). «Abordar la interculturalidad en el aula desde el desarrollo de la competencia intercultural del profesorado». MarcoELE: Revista de didáctica ELE, 22.

NúÑEZ PARÍS, Félix (2002). «Memoria y estilos de aprendizaje en la enseñanza del francés como lengua extranjera». CAUCE, Revista Internacional de Filología y su Didáctica, 31, 259-273.

Quintanilla ESPINIZA, Angie; Anita FERREIRA CABRERA (2010). «Habilidades comunicativas en L2 mediatizadas por la tecnología en el contexto de los enfoques por tareas y cooperative». Estudios pedagógicos, 36, 2.

SÁNCHEZ BENÍTEZ, Gema (2010). «Las estrategias de aprendizaje a través del componente lúdico». MarcoELE: Revista de didáctica ELE, 11.

Young, Shawn; Devin Young y Lauren Yong (2016). Classcraft. Recuperado el 10/04/2018, de https://www.classcraft.com. 
ANEXo: CARTAS

Actividad: ¿A qué sabe?

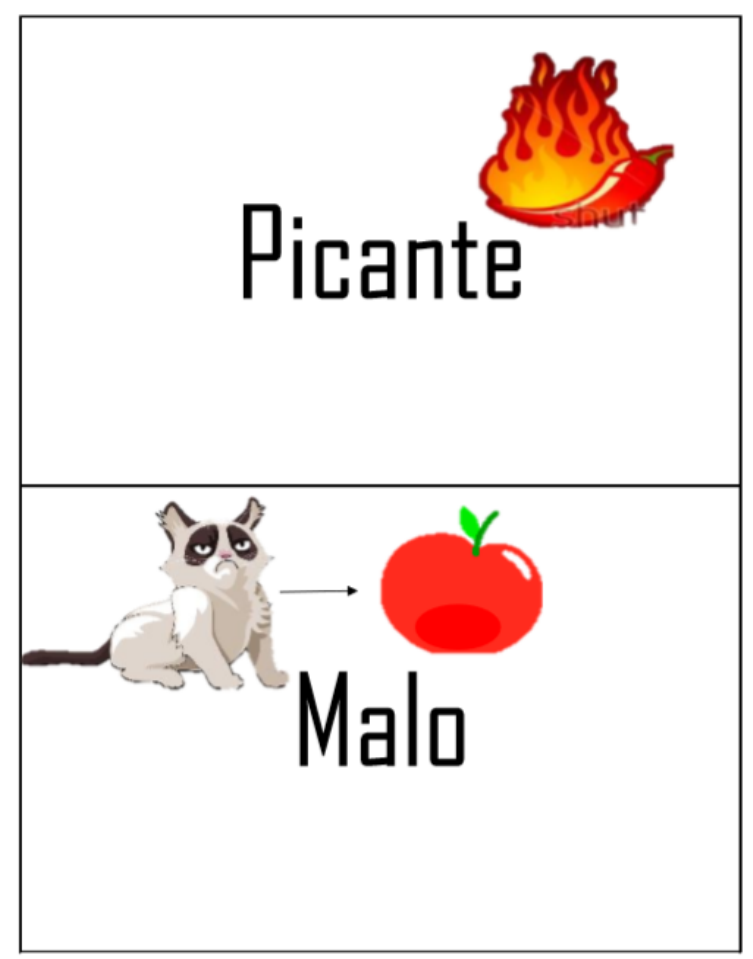

Salado

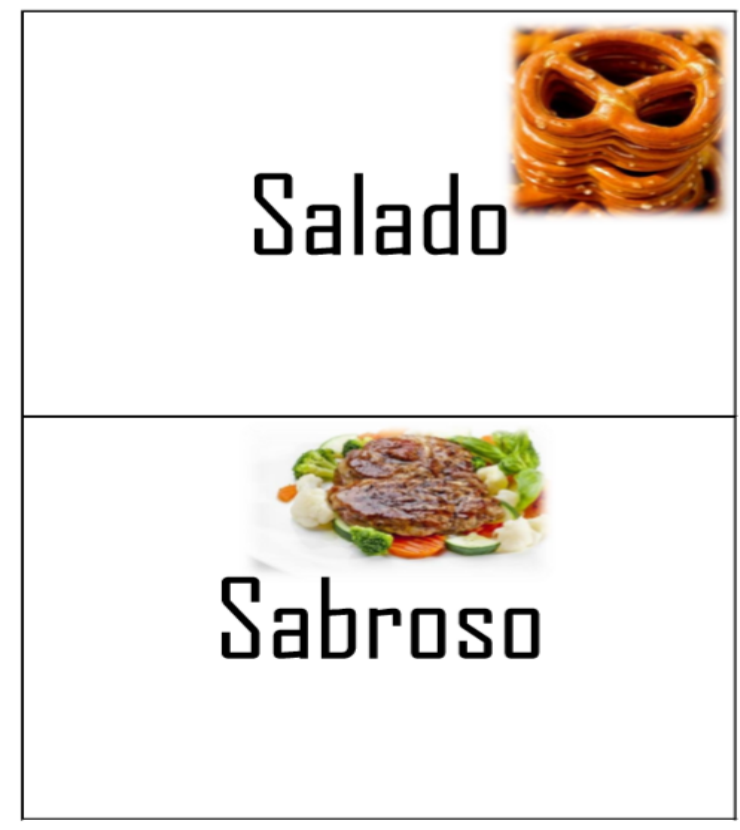



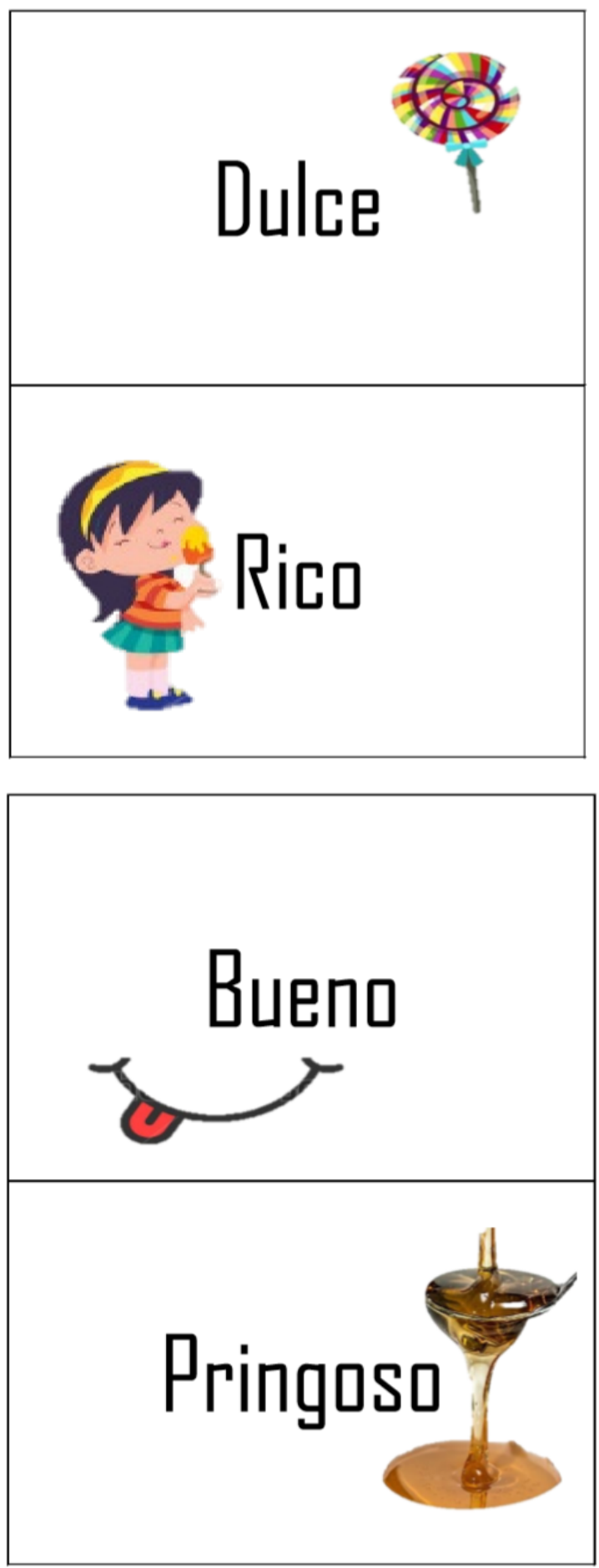


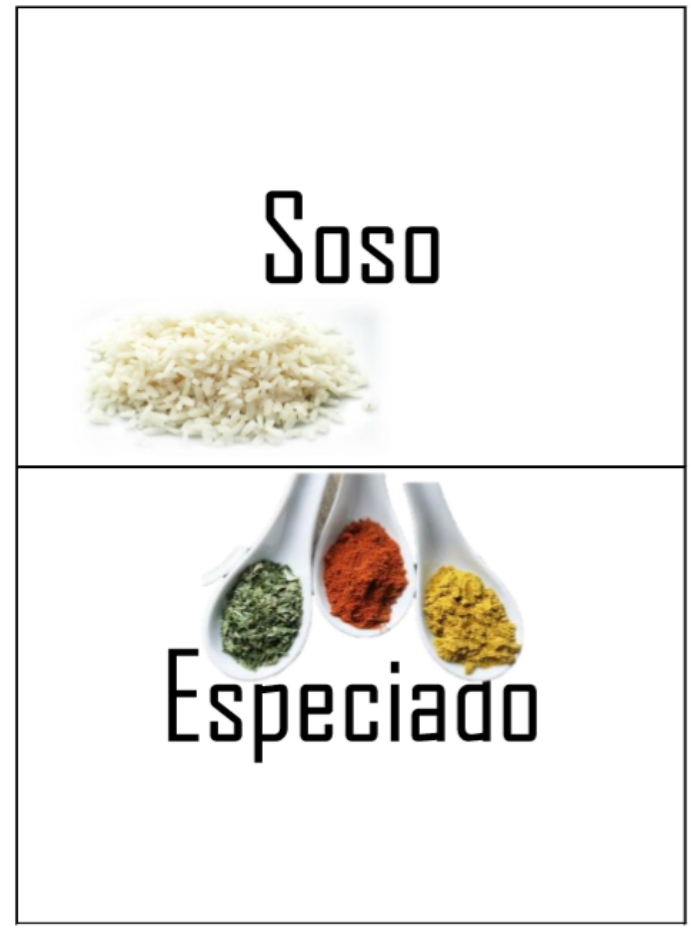


Actividad: Cartas contra estudiantes de E/LE:

1) Cartas de pregunta

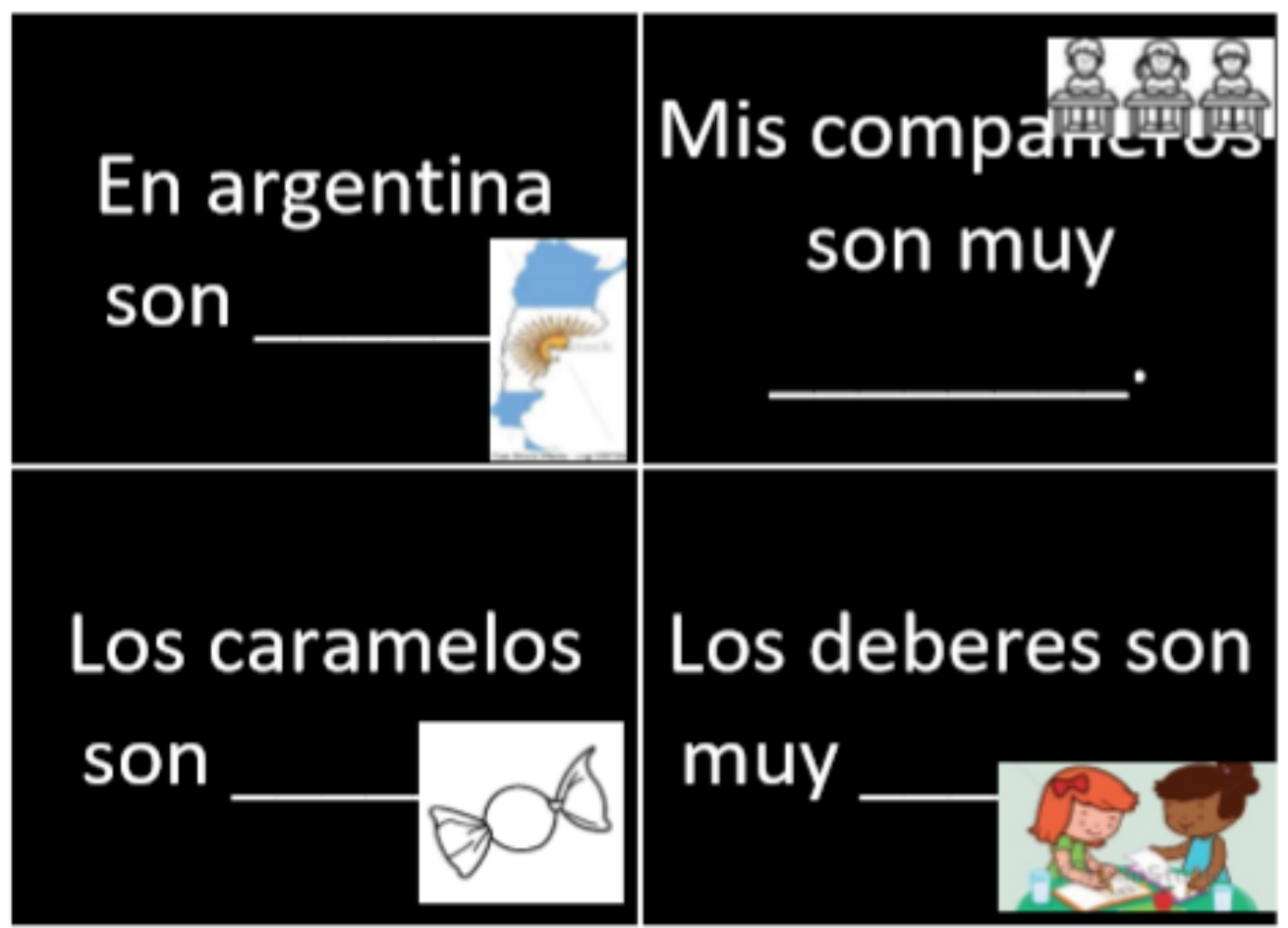




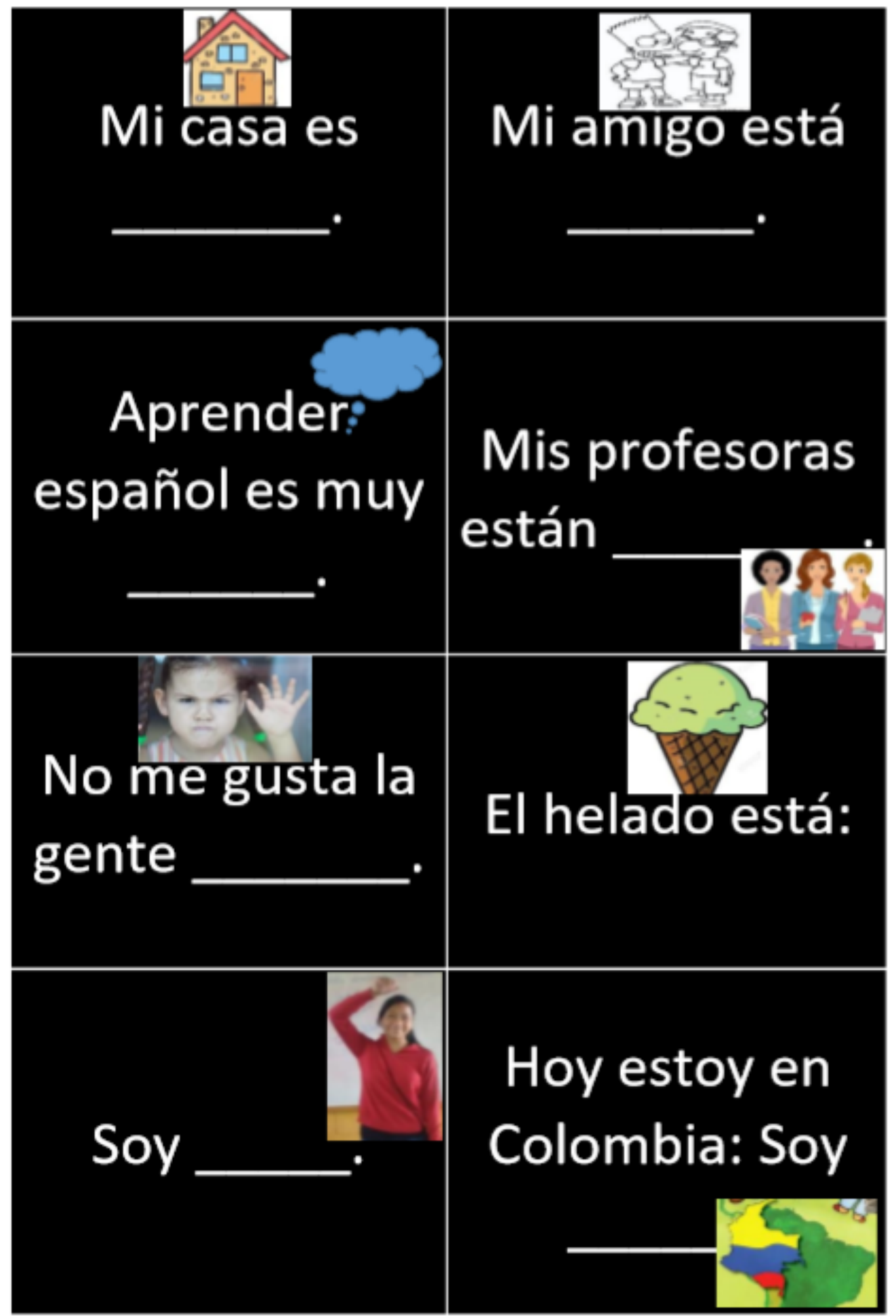




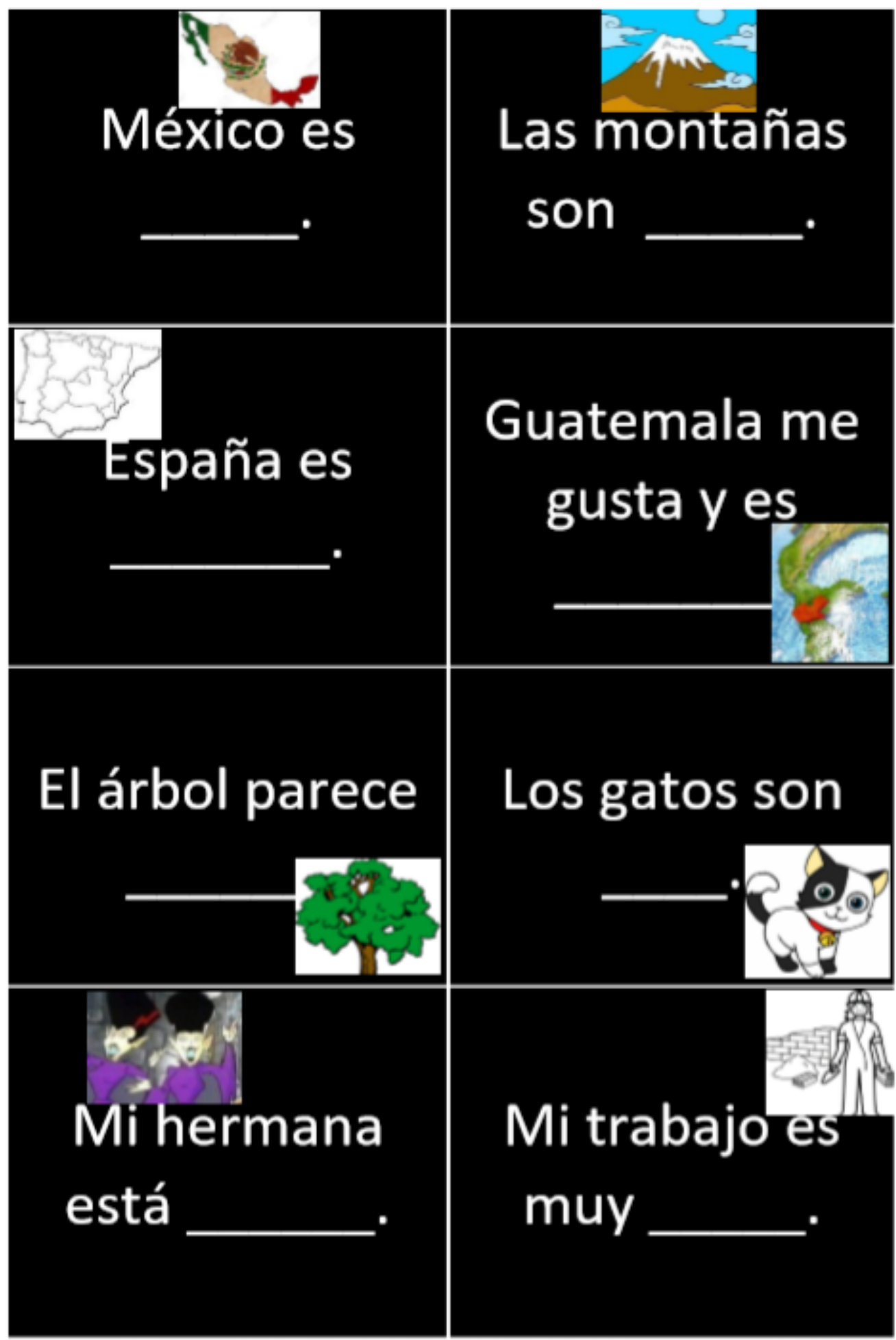




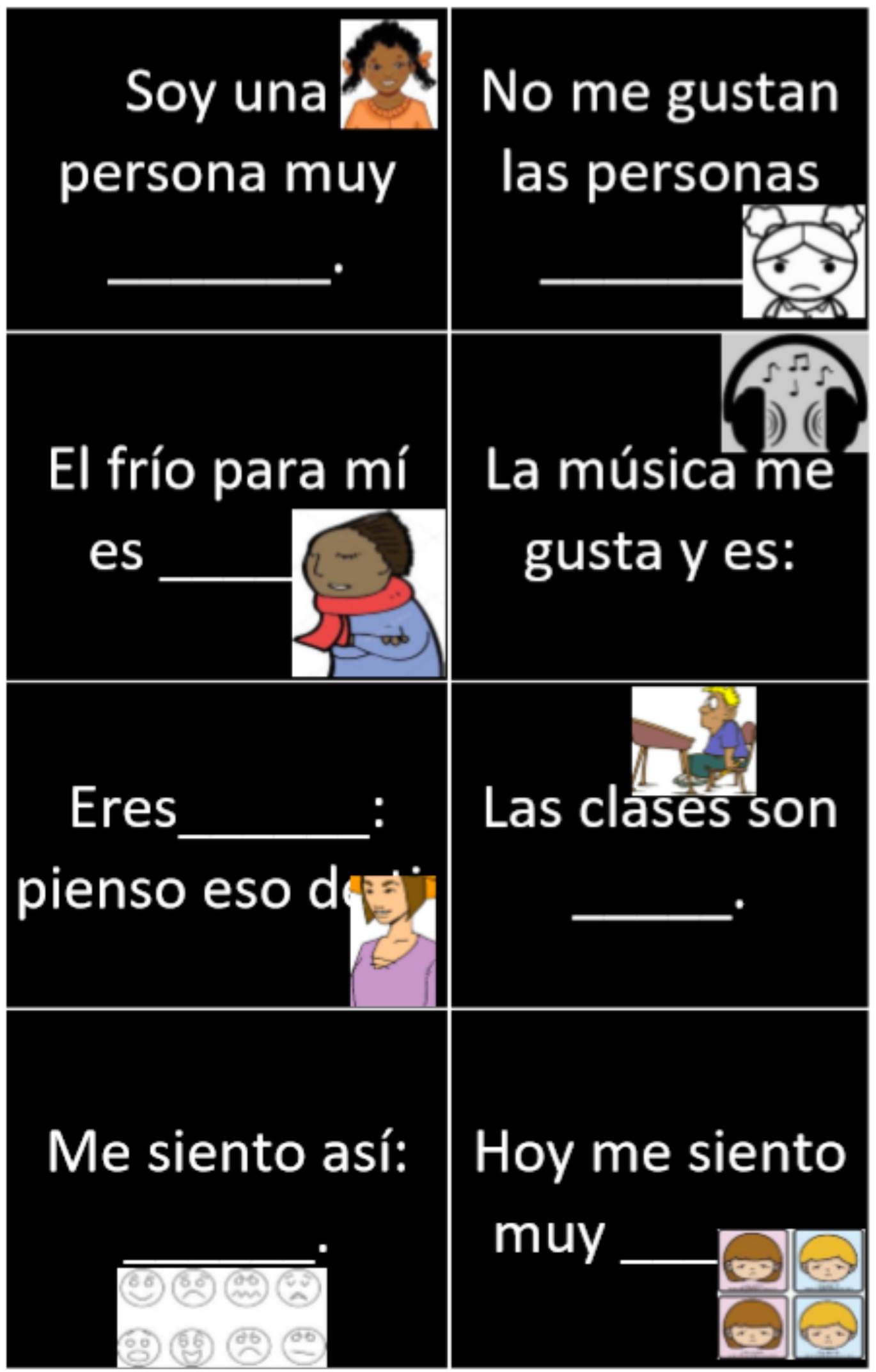


Nada es

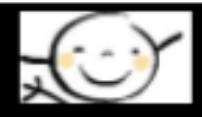

Soy

me gusta sonreír.

Me gusta ser

Mi amiga está

El vecino está Los deportes todo el me hacen estar

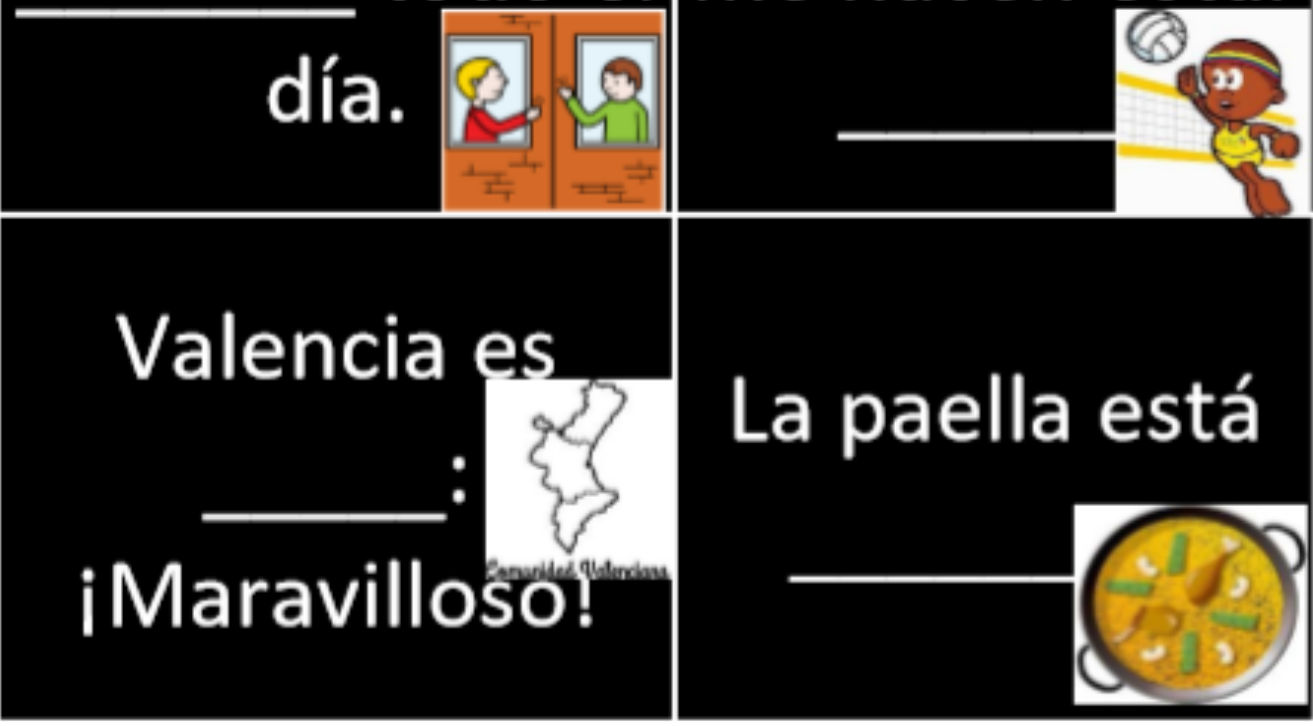


2) Cartas de repuesta:

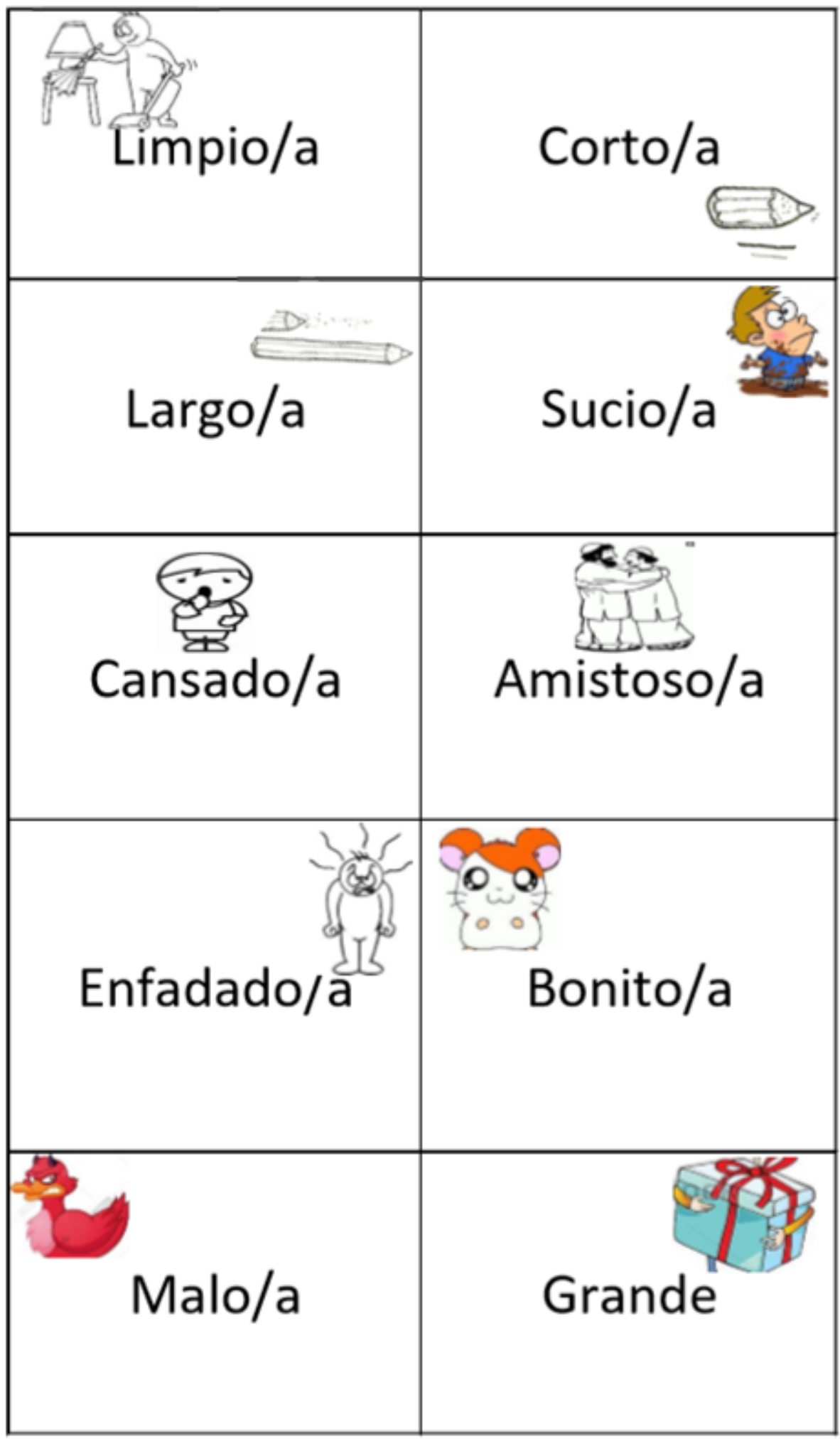




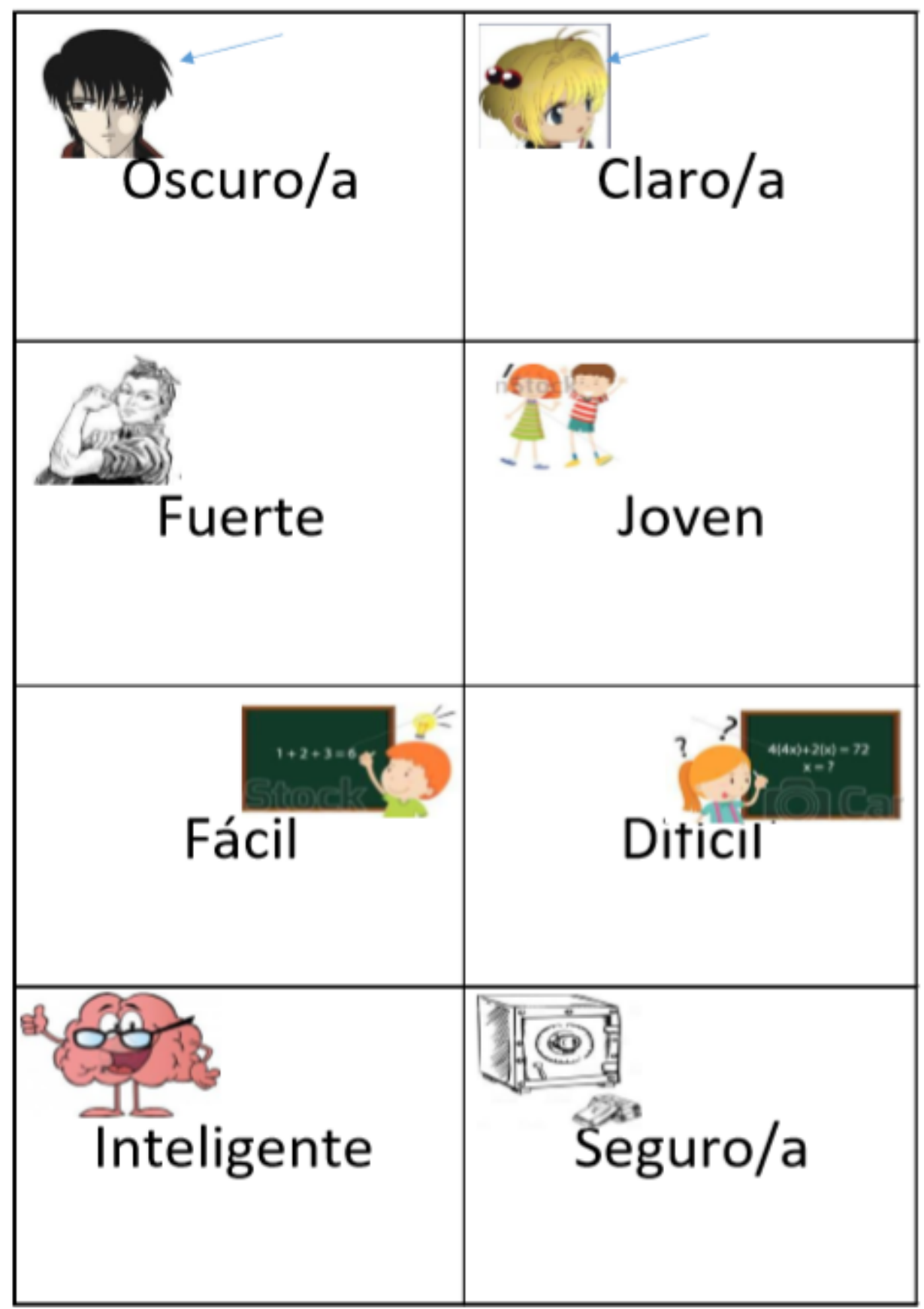




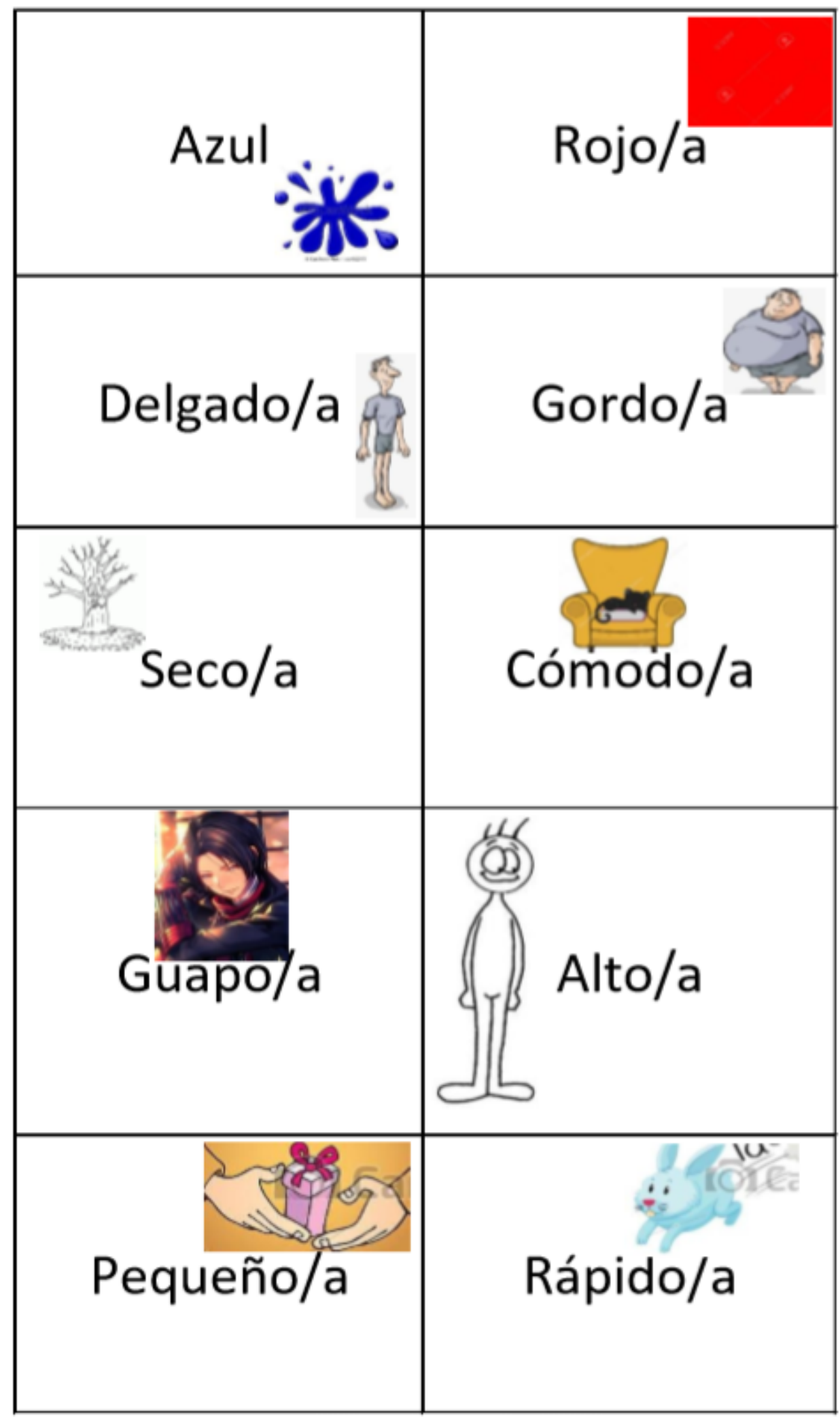




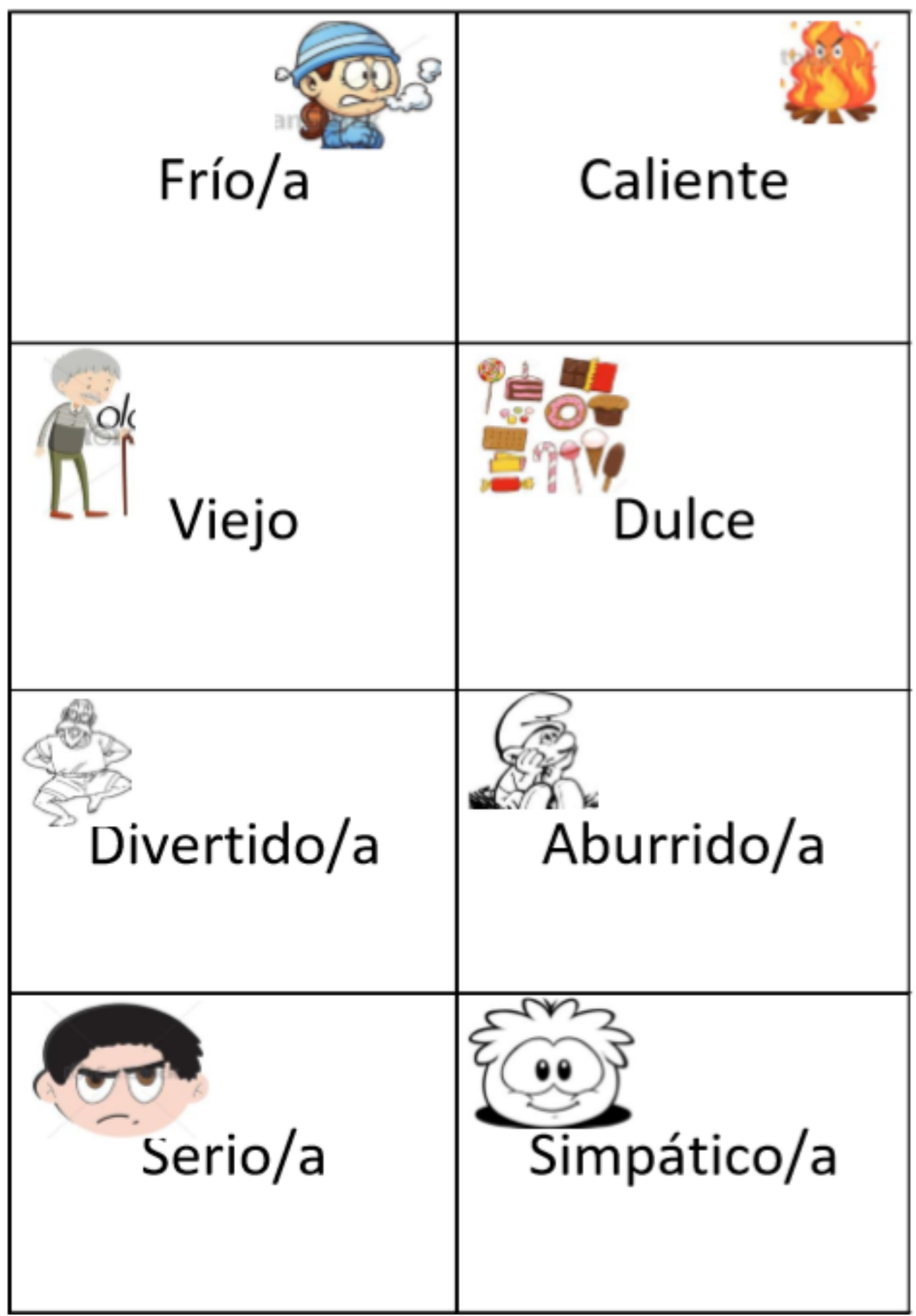




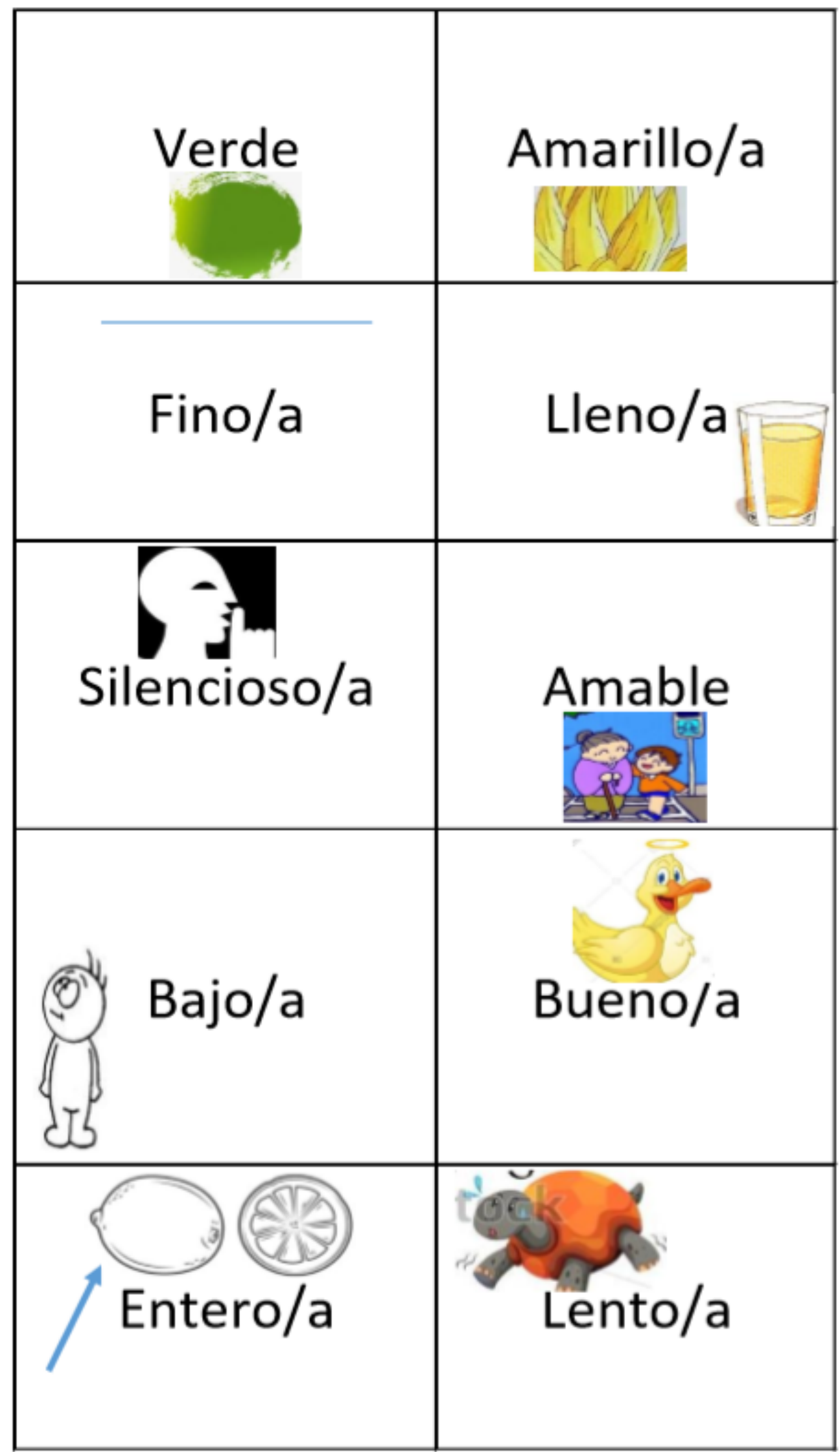




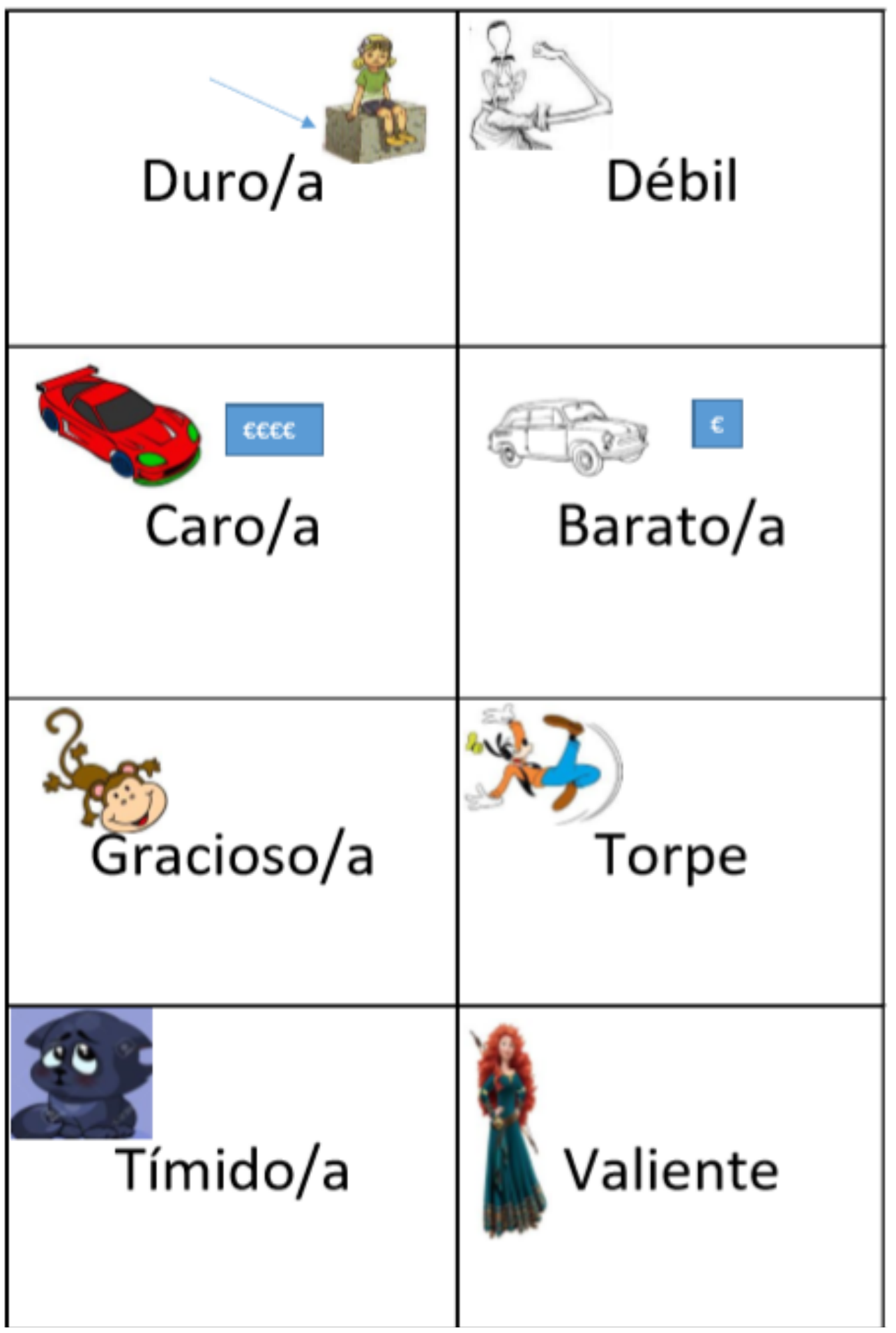

